\title{
ON HAMILTONIAN FORMULATIONS AND CONSERVATION LAWS FOR PLATE THEORIES OF VEKUA-AMOSOV TYPE
}

\author{
Sergey I. Zhavoronok \\ Institute of Applied Mechanics of Russian Academy of Sciences, Moscow, RUSSIA \\ Moscow Aviation Institute (National Research University), Moscow, RUSSIA
}

\begin{abstract}
Some variants of the generalized Hamiltonian formulation of the plate theory of I. N. Vekua - A. A. Amosov type are presented. The infinite dimensional formulation with one evolution variable, or an "instantaneous" formalism, as well as the de Donder - Weyl one are considered, and their application to the numerical simulation of shell and plate dynamics is briefly discussed. The main conservation laws are formulated for the general plate theory of $\mathrm{N}^{\text {th }}$ order, and the possible motion integrals are introduced.
\end{abstract}

Keywords: refined shell theory, analytical mechanics of continua, Hamiltonian formalism, de Donder - Weyl formulation, conservation laws

\section{О ГАМИЛЬТОНОВЫХ ФОРМУЛИРОВКАХ И ЗАКОНАХ СОХРАНЕНИЯ В ТЕОРИЯХ ПЛАСТИН ТИПА И.Н. ВЕКУА - А.А. АМОСОВА}

\author{
С.И. Жаворонок \\ Институт прикладной механики Российской академии наук, Москва, Россия \\ Московский авиационный институт (Национальный исследовательский университет), Москва, Россия
}

\begin{abstract}
Резюме: Предложены различные варианты обобщенных гамильтоновых формулировок общей теории оболочек типа И.Н. Векуа - А.А. Амосова. Рассмотрены формулировки на базе бесконечномерного фазового пространства с одной эволюционной переменной, а также на основе формализма де Дондера Вейля, обсуждаются возможности их приложения к численным решениям задач механики тонкостенных систем. Получены основные законы сохранения для теории оболочек $N$-го порядка и определены основные первые интегралы системы.
\end{abstract}

Ключевые слова: теория оболочек высшего порядка, аналитическая механика континуальных систем, формализм Гамильтона, формулировка де Дондера - Вейля, законы сохранения

\section{INTRODUCTION}

The modern theory of shells and plates deals with many different problems in thin-walled structures' mechanics [1]. One can note that “...new, more reliable 2D multi-field models are needed... for high-frequency vibrations of shells" [2] (see also [3-7]), in particular for functionally graded structures [8-10], as well as for wave propagation problems [11-13] and in the transient plate and shell dynamics [14]. A lot of different refined models for plates and shells exist, for instance the ones based on power series extension [4, 5, 8], or using the asymptotic integration $[11-13,15,16]$. An efficient approach that allows one to construct the hierarchy of various order shell and plate models was constructed by I.N. Vekua [17] on the basis of orthogonal series and further improved in [18-20]; this type of shell theories has shown its efficiency in dynamics, especially for transient problems [21].

The new variant of the shell theory of I. N. Vekua type obtained by A.A. Amosov [22, 23] is based on the use of the tensor algebra; it offers the improved formalization level close to the one of the finite element method [23, 24]. The further improvement of the Vekua Amosov higher order theory of shells and plates consists in the use of Lagrangian formalism of 
analytical mechanics extended to continuum systems [24-27].

The Lagrangian formulation of refined plate models is quite efficient in steady dynamics problems such as $[28,29]$. At the same time it is known that the Hamiltonian approach [30] provides some advantages (e. g. see [31]). Some attempts to use the features of symplecticity of Hamiltonian structures in statics were made in [32-35] where the so-called "instantaneous" formalism was applied and the Hamiltonian systems with operator coefficients were studied (an approach similar to [36-38]). This way leads to first-order "evolution" differential equations in time domain with second-order spatial derivatives. An alternative approach proposed by N.A. Kilchevskiy [39] deals with the Legendre transform considering both time and space derivatives; it leads to the finite dimensional phase space formalism well known in the general field theory as a "polymomentum formalism" [40, 41]. Various types of Lepagean equivalents may be used to obtain different Hamiltonian systems while the simplest one corresponds to the de Donder - Weyl formalism [40]. Both "instantanelus" and de Donder formulations for the plate theory of Nth order are constructed below, and main conservation laws are considered.

\section{FUNDAMENTALS OF THE PLATE THEORY OF NTH ORDER}

Let the plate be a three-dimensional body bounded by face planes $S_{ \pm}$and a lateral surface $S_{B}$ [23-27, 47], with the mid-plane $S$ and the plate thickness denoted as $2 h$ [25].

$$
\begin{gathered}
V \subset \square^{3}, \bar{V}=V \cup \partial V, \partial V=S_{B} \oplus S_{ \pm} ; \\
\forall M_{*} \in \bar{V}, M \in S \quad \mathbf{R}\left(M_{*}\right)=\mathbf{r}(M)+h \zeta \mathbf{n} .
\end{gathered}
$$

The two-dimensional model of a plate consists in the two-dimensional manifold $S$,

$$
\bar{S}=S \cup\left(\partial S=S \cap S_{B}\right)
$$

with the curvilinear chart $\xi^{\alpha} \in D_{\xi} \subseteq \square^{2}$, $\alpha=1,2$, so that $\forall M \in \bar{S} \mathbf{R}(M) \equiv \mathbf{r}\left(\xi^{\alpha}\right)$. Two base vectors

$$
\mathbf{r}_{\alpha}=\partial_{\alpha} \mathbf{r}, \partial_{\alpha} \equiv \partial / \partial \xi^{\alpha}
$$

corresponding to $\xi^{\alpha}$ induce the metrics

$$
a_{\alpha \beta}=\mathbf{r}_{\alpha} \cdot \mathbf{r}_{\beta} ;
$$

the normal unit is defined as

$$
\mathbf{n}=a^{-1 / 2}\left(\mathbf{r}_{1} \times \mathbf{r}_{2}\right), a=\operatorname{det} a_{\alpha \beta} .
$$

Let

$$
\mathbf{u}=u_{\alpha} \mathbf{r}^{\alpha}+u_{3} \mathbf{n}
$$

be the spatial displacement vector field. Thus, the three-dimensional problem statement of elasticity theory is based on the Hamilton principle $[25,26]$ :

$$
\delta \int_{t_{0}}^{t_{1}}\left(\int_{V} \mathcal{L}_{V} d V+\int_{\partial V} \mathcal{L}_{\partial V} d S\right) d t=0
$$

Let us consider the Lagrangian continuum system defined within the configuration manifold $\Omega_{N}$ with the field variables of the $1^{\text {st }}$ kind $u_{\alpha}^{(k)}, u_{3}^{(k)}$ being the expansion factors of the spatial displacement field $\mathbf{u}$ with respect to the biorthogonal function system $p_{(k)}(\zeta)$, $p^{(k)}(\zeta)[26,27]$, so that we have

$$
\mathbf{u}\left(t, \xi^{\alpha}, \zeta\right) \approx\left(u_{\alpha}^{(k)} \mathbf{r}^{\alpha}+u_{3}^{(k)} \mathbf{n}\right) p_{(k)}(\zeta), k=\overline{0, N} .
$$

Here the components $u_{\alpha}\left(t, \xi^{\alpha}, \zeta\right), u_{3}\left(t, \xi^{\alpha}, \zeta\right)$ are assumed to be square integrable over 
$[-1,1] \ni \zeta[25-27]$. In general, the convergence is supposed folloving [15].

The Lagrangian densitiy can be now defined on $S$ and $\partial S$ as follows $[33,35]$ :

$$
\begin{aligned}
& \mathcal{L}_{\mathrm{S}}\left(u_{\alpha}^{(k)}, u_{3}^{(k)}, \dot{u}_{\alpha}^{(k)}, \dot{u}_{3}^{(k)}, \bar{\nabla}_{\beta} u_{\alpha}^{(k)}, \bar{\nabla}_{\beta} u_{3}^{(k)}\right)= \\
&= \frac{1}{2} \rho_{(k)}^{(m)}\left(\dot{u}_{(m)}^{\alpha} \dot{u}_{\alpha}^{(k)}+\dot{u}_{(m)}^{3} \dot{u}_{3}^{(k)}\right)+F_{(k)}^{i} u_{i}^{(k)}- \\
&-\frac{1}{2}\left(C_{(k m)}^{\alpha \beta \gamma \delta} \bar{\nabla}_{\gamma} u_{\delta}^{(m)}+C_{(k m)}^{\alpha \beta 3} u_{3}^{(m)}\right) \bar{\nabla}_{\beta} u_{\alpha}^{(k)}- \\
&-\frac{1}{2}\left(C_{(k m)}^{3 \beta \gamma 3} \bar{\nabla}_{\gamma} u_{3}^{(m)}+C_{(k m)}^{3 \beta \gamma} u_{\gamma}^{(m)}\right) \bar{\nabla}_{\beta} u_{3}^{(k)}- \\
&-\frac{1}{2} h^{-1}\left(C_{(k m)}^{33 \gamma \delta} \bar{\nabla}_{\gamma} u_{\delta}^{(m)}+C_{(k m)}^{333} u_{3}^{(m)}\right) D_{(n \neg)}^{([k)} u_{3}^{(n)}- \\
&-\frac{1}{2} h^{-1}\left(C_{(k m)}^{\alpha 3 \gamma 3} \bar{\nabla}_{\gamma} u_{3}^{(m)}+C_{(k m)}^{\alpha 3 \gamma} u_{\gamma}^{(m)}\right) D_{(n \sqsupset)}^{(k)} u_{\alpha}^{(n)} ; \\
& \mathcal{L}_{\partial \mathrm{S}}\left(u_{\alpha}^{(k)}, u_{3}^{(k)}\right)=q_{B(k)}^{\alpha} u_{\alpha}^{(k)}+q_{B(k)}^{\alpha} u_{\alpha}^{(k)} .
\end{aligned}
$$

Here $\bar{\nabla}$ denotes the covariant derivative and $D_{(\mathrm{m})}^{(k \sqsupset)}$ are linear operators (see [23-29]):

$$
\begin{aligned}
& \rho_{(k)}^{(m)}=\left(\rho p^{(m)}, p_{(k)}\right)_{1} ; \quad D_{(n)}^{(k)}=\left(d p_{(n)} / d \zeta, p^{(k)}\right)_{1} ; \\
& C_{(k m)}^{333}=h^{-1} D_{(k\urcorner)}^{(\neg n)} C_{(n m)}^{3333} ; \quad C_{(k m)}^{\alpha \beta 3}=h^{-1} D_{(k \rrbracket)}^{(\llbracket n)} C_{(n m)}^{\alpha \beta 33} ; \\
& C_{(k m)}^{3 \beta \gamma}=h^{-1} D_{(k \downarrow)}^{(\ulcorner n)} C_{(n m)}^{3 \beta 3 \gamma} ; \quad C_{(k m)}^{\alpha \beta 3}=h^{-1} D_{(k\rceil)}^{(\llbracket n)} C_{(n m)}^{\alpha 3 \beta 3} .
\end{aligned}
$$

Thus, the plate is defined as a two-dimensional continuum system within the field variables $u_{\alpha}^{(k)}, u_{3}^{(k)}$ and the Lagrangian densities $\mathcal{L}_{S}, \mathcal{L}_{\partial S}$. Finally, the generalized Lagrange equations of the second kind [25]

$$
\begin{aligned}
& \partial_{t} \frac{\partial \mathcal{L}_{S}}{\partial \dot{u}_{\alpha}^{(k)}}+\bar{\nabla}_{\beta} \frac{\partial \mathcal{L}_{S}}{\partial \bar{\nabla}_{\beta} u_{\alpha}^{(k)}}-\frac{\partial \mathcal{L}_{S}}{\partial u_{\alpha}^{(k)}}=0 ; \\
& \partial_{t} \frac{\partial \mathcal{L}_{S}}{\partial \dot{u}_{3}^{(k)}}+\bar{\nabla}_{\beta} \frac{\partial \mathcal{L}_{S}}{\partial \bar{\nabla}_{\beta} u_{3}^{(k)}}-\frac{\partial \mathcal{L}_{S}}{\partial u_{3}^{(k)}}=0
\end{aligned}
$$

can be formulated in the particular case of the Nth order plate theory as (2.4) (e. g. see [25])

$$
\begin{aligned}
& \rho_{(k)}^{(m)} \ddot{u}_{(m)}^{\alpha}=\bar{\nabla}_{\beta} \sigma_{(k)}^{\alpha \beta}-h^{-1} D_{(k \cdot)}^{(\cdot m)} \sigma_{(m)}^{\alpha 3}+\bar{F}_{(k)}^{\alpha} ; \\
& \rho_{(k)}^{(m)} \ddot{u}_{(m)}^{3}=\bar{\nabla}_{\beta} \sigma_{(k)}^{3 \beta}-h^{-1} D_{(k \cdot)}^{(\cdot m)} \sigma_{(m)}^{33}+\bar{F}_{(k)}^{3} ;
\end{aligned}
$$

as well their natural boundary conditions (2.5)

$$
\begin{aligned}
& \left.\left(\sigma_{(k)}^{\alpha \beta} v_{\beta}-q_{B(k)}^{\alpha}\right) \delta u_{\alpha}^{(k)}\right|_{S_{B}}=0 ; \\
& \left.\left(\sigma_{(k)}^{3 \beta} v_{\beta}-q_{B(k)}^{3}\right) \delta u_{3}^{(k)}\right|_{S_{B}}=0 ;
\end{aligned}
$$

while the corresponding initial conditions can be written as (2.6) (see [24-26]):

$$
\begin{aligned}
& \left.u_{\alpha}^{(k)}\right|_{t=t_{0}}=U_{\alpha}^{(k)} ;\left.u_{3}^{(k)}\right|_{t=t_{0}}=U_{3}^{(k)} ; \\
& \left.\dot{u}_{\alpha}^{(k)}\right|_{t=t_{0}}=V_{\alpha}^{(k)} ;\left.\dot{u}_{3}^{(k)}\right|_{t=t_{0}}=V_{3}^{(k)} .
\end{aligned}
$$

Let us note that the generalized tangential and shear forces can be defined by the partial derivatives of the Lagrangian density $\mathcal{L}_{S}$ :

$$
\sigma_{(k)}^{\alpha \beta}=-\frac{\partial \mathcal{L}_{S}}{\partial \bar{\nabla}_{\beta} u_{\alpha}^{(k)}}, \sim \smile \frac{3 \beta}{(\bar{k})} \quad \frac{\partial \mathcal{L}_{S}}{\partial \bar{\nabla}_{\beta} u_{3}^{(k)}} .
$$

Finally, the total Lagrangian for the plate can be determined as follows:

$$
L=\int_{S} \mathcal{L}_{S} d S \int_{\partial S} \mathcal{L}_{\partial S} d \Gamma
$$

\section{ENERGY AND MOMENTUM CONSERVATION LAWS IN THE PLATE THEORY OF NTH ORDER}

Let us define the total time derivative of the Lagrangian densities given by (2.2): 


$$
\begin{gathered}
\frac{d}{d t} \mathcal{L}_{S}\left(u_{\alpha}^{(k)}, u_{3}^{(k)}, \dot{u}_{\alpha}^{(k)}, \dot{u}_{3}^{(k)}, \bar{\nabla}_{\beta} u_{\alpha}^{(k)}, \bar{\nabla}_{\beta} u_{3}^{(k)}\right)= \\
=\frac{\partial \mathcal{L}_{S}}{\partial u_{\alpha}^{(k)}} \dot{u}_{\alpha}^{(k)}+\frac{\partial \mathcal{L}_{S}}{\partial u_{3}^{(k)}} \dot{u}_{3}^{(k)}+\frac{\partial \mathcal{L}_{S}}{\partial \dot{u}_{\alpha}^{(k)}} \ddot{u}_{\alpha}^{(k)}+\frac{\partial \mathcal{L}_{S}}{\partial u_{3}^{(k)}} \ddot{u}_{3}^{(k)}+ \\
+\frac{\partial \mathcal{L}_{S}}{\partial \bar{\nabla}_{\beta} u_{\alpha}^{(k)}} \bar{\nabla}_{\beta} \dot{u}_{\alpha}^{(k)}+\frac{\partial \mathcal{L}_{S}}{\partial \bar{\nabla}_{\beta} u_{3}^{(k)}} \bar{\nabla}_{\beta} \dot{u}_{3}^{(k)} ; \\
\frac{d}{d t} \mathcal{L}_{\partial S}\left(u_{\alpha}^{(k)}, u_{3}^{(k)}\right)=\bar{q}_{(k)}^{\alpha} \dot{u}_{\alpha}^{(k)}+\bar{q}_{(k)}^{3} \dot{u}_{3}^{(k)} .
\end{gathered}
$$

Accounting for the Gauss-Ostrogradsky theorem, we can represent the corresponding time derivative for the total Lagrangian as

$$
\begin{gathered}
\int_{S} \frac{d \mathcal{L}_{S}}{d t} d S+\int_{\partial S} \frac{d \mathcal{L}_{\partial S}}{d t} d \Gamma= \\
=\int_{S} \frac{d}{d t}\left(\frac{\partial \mathcal{L}_{S}}{\partial \dot{u}_{\alpha}^{(k)}} \dot{u}_{\alpha}^{(k)}+\frac{\partial \mathcal{L}_{S}}{\partial \dot{u}_{3}^{(k)}} \dot{u}_{3}^{(k)}\right) d S+ \\
-\int_{S}\left[\partial_{t} \frac{\partial \mathcal{L}_{S}}{\partial \dot{u}_{\alpha}^{(k)}}+\bar{\nabla}_{\beta} \frac{\partial \mathcal{L}_{S}}{\partial \bar{\nabla}_{\beta} u_{\alpha}^{(k)}}-\frac{\partial \mathcal{L}_{S}}{\partial u_{\alpha}^{(k)}}\right] \dot{u}_{\alpha}^{(k)} d S- \\
-\int_{S}\left[\partial_{t} \frac{\partial \mathcal{L}_{S}}{\partial \dot{u}_{3}^{(k)}}+\bar{\nabla}_{\beta} \frac{\partial \mathcal{L}_{S}}{\partial \bar{\nabla}_{\beta} u_{3}^{(k)}}-\frac{\partial \mathcal{L}_{S}}{\partial u_{3}^{(k)}}\right] \dot{u}_{3}^{(k)} d S+ \\
+\int_{\partial S}\left(\frac{\partial \mathcal{L}_{S}}{\partial \bar{\nabla}_{\beta} u_{\alpha}^{(k)}} \dot{u}_{\alpha}^{(k)}+\frac{\partial \mathcal{L}_{S}}{\partial \bar{\nabla}_{\beta} u_{3}^{(k)}} \dot{u}_{3}^{(k)}\right) v_{\beta} d \Gamma- \\
+\int_{\partial S}\left(\frac{\partial \mathcal{L}_{\partial S}}{\partial u_{\alpha}^{(k)}} \dot{u}_{\alpha}^{(k)}+\frac{\partial \mathcal{L}_{\partial S}}{\partial u_{3}^{(k)}} \dot{u}_{3}^{(k)}\right) d \Gamma .
\end{gathered}
$$

Taking into account the generalized Lagrange equations of the second kind (2.3) for the plate theory of $\mathrm{N}^{\text {th }}$ order [25-27] coinciding with the square-bracketed terms in (3.1) as well as their natural boundary conditions (2.5), we can write the total time derivative using the following representation:

$$
\begin{aligned}
\frac{d H^{0}}{d t} & \left.=\int_{\partial S}\left(\sigma_{(k)}^{\alpha \beta} v_{\beta}-\bar{q}_{B(k)}^{\alpha}\right) \dot{u}_{\alpha}^{(k)} d \quad\right] \\
& +\int_{\partial S}\left(\sigma_{(k)}^{3 \beta} v_{\beta}-\bar{q}_{B(k)}^{3}\right) \dot{u}_{3}^{(k)} d \Gamma,
\end{aligned}
$$

where the Hamiltonian is defined as follows:

$$
H^{0}=\int_{S} \mathcal{H}^{0} d S
$$

The surface density of the Hamiltonian $\mathcal{H}^{0}$ is constructed by means of the Legendre transform of the Lagrangian surface density $\mathcal{L}_{S}$ considering only time derivatives of the field variables $\dot{u}_{\alpha}^{(k)}, \dot{u}_{3}^{(k)}$ in terms of the so-called "infinite dimensional phase space", or “instantaneous" formulation [30, 42]:

$$
\mathcal{H}^{0}=p_{\alpha}^{(k)} \dot{u}_{(k)}^{\alpha}+p_{3}^{(k)} \dot{u}_{(k)}^{3}-\mathcal{L}_{S},
$$

where the generalized momenta of the $k$-ке order are determined by the formulae

$$
\begin{aligned}
& p_{(k)}^{\alpha}=\frac{\partial \mathcal{L}_{S}}{\partial \dot{u}_{\alpha}^{(k)}}={ }_{\sim_{(k)}^{(m)}}^{(m)} \dot{u}_{(m)}^{\alpha} ; \\
& p_{3}^{(k)}=\frac{\partial \mathcal{L}_{S}}{\partial \dot{u}_{3}^{(k)}}={ }_{*}^{(m)}{ }_{(k)}^{(m)} \dot{u}_{(m)}^{3} .
\end{aligned}
$$

The formula (3.3) yields that $H^{0}$ is the total energy; it follows from (2.2) and (3.4). It can be seen that the bracketed terms in (3.2) coincide with (2.5), therefore the total energy $H^{0}$ becomes the integral of motion for the plate if the boundary conditions on $\partial S$ are exactly satisfied. Thus, the formula (3.2) defines the energy conservation. Moreover we can obtain the differential formulation of the conservation law for the energy density $\mathcal{H}^{0}$ :

$$
\dot{\mathcal{H}}^{0}=-\bar{\nabla}_{\beta} S^{\beta}
$$

here $\mathbf{S}=S^{\beta} \mathbf{r}_{\beta}$ is the tangent vector field of the energy flux [43]:

$$
S^{\beta}=-s_{(k)}^{\alpha \beta} \dot{u}_{\alpha}^{(k)} \quad s_{(k)}^{3 \beta} \dot{u}_{3}^{(k)} .
$$

This quantity can be useful, in particular, for waveguide problems such as [28, 29]. 
Now let us consider the total derivatives of the Lagrangian densities with respect to the surface coordinates $\xi^{\gamma}$ :

$$
\begin{gathered}
\frac{d}{d \xi^{\gamma}} \mathcal{L}_{S}\left(u_{\alpha}^{(k)}, u_{3}^{(k)}, \dot{u}_{\alpha}^{(k)}, \dot{u}_{3}^{(k)}, \bar{\nabla}_{\beta} u_{\alpha}^{(k)}, \bar{\nabla}_{\beta} u_{3}^{(k)}\right)= \\
=\frac{\partial \mathcal{L}_{S}}{\partial u_{\alpha}^{(k)}} \bar{\nabla}_{\gamma} u_{\alpha}^{(k)}+\frac{\partial \mathcal{L}_{S}}{\partial u_{3}^{(k)}} \bar{\nabla}_{\gamma} u_{3}^{(k)}+ \\
+\frac{\partial \mathcal{L}_{S}}{\partial \dot{u}_{\alpha}^{(k)}} \bar{\nabla}_{\gamma} \dot{u}_{\alpha}^{(k)}+\frac{\partial \mathcal{L}_{S}}{\partial u_{3}^{(k)}} \bar{\nabla}_{\gamma} \dot{u}_{3}^{(k)}+ \\
+\frac{\partial \mathcal{L}_{S}}{\partial \bar{\nabla}_{\beta} u_{\alpha}^{(k)}} \bar{\nabla}_{\gamma} \bar{\nabla}_{\beta} \dot{u}_{\alpha}^{(k)}+\frac{\partial \mathcal{L}_{S}}{\partial \bar{\nabla}_{\beta} u_{3}^{(k)}} \bar{\nabla}_{\gamma} \bar{\nabla}_{\beta} \dot{u}_{3}^{(k)} \\
\frac{d \mathcal{L}_{\partial S}}{d \xi^{\gamma}}=\bar{q}_{(k)}^{\alpha} \bar{\nabla}_{\gamma} u_{\alpha}^{(k)}+\bar{q}_{(k)}^{3} \bar{\nabla}_{\gamma} u_{3}^{(k)} .
\end{gathered}
$$

Keeping in mind that the Riemann-Christoffel tensor of the plane $S$ vanishes,

$$
R_{\alpha \beta i \square}^{\square j}=0,
$$

and for the Gauss-Ostrogradsky theorem, we have

$$
\begin{gathered}
\int_{S} \frac{d \mathcal{L}_{S}}{d \xi^{\gamma}} d S+\int_{\partial S} \frac{d \mathcal{L}_{\partial S}}{d \xi^{\gamma}} d \Gamma= \\
=\int_{S} \frac{d}{d t}\left(\frac{\partial \mathcal{L}_{S}}{\partial \dot{u}_{\alpha}^{(k)}} \bar{\nabla}_{\gamma} u_{\alpha}^{(k)}+\frac{\partial \mathcal{L}_{S}}{\partial \dot{u}_{3}^{(k)}} \bar{\nabla}_{\gamma} u_{3}^{(k)}\right) d S- \\
-\int_{S}\left[\partial_{t} \frac{\partial \mathcal{L}_{S}}{\partial \dot{u}_{\alpha}^{(k)}}+\bar{\nabla}_{\beta} \frac{\partial \mathcal{L}_{S}}{\partial \bar{\nabla}_{\beta} u_{\alpha}^{(k)}}-\frac{\partial \mathcal{L}_{S}}{\partial u_{\alpha}^{(k)}}\right] \bar{\nabla}_{\gamma} u_{\alpha}^{(k)} d S- \\
-\int_{S}\left[\partial_{t} \frac{\partial \mathcal{L}_{S}}{\partial \dot{u}_{3}^{(k)}}+\bar{\nabla}_{\beta} \frac{\partial \mathcal{L}_{S}}{\partial \bar{\nabla}_{\beta} u_{3}^{(k)}}-\frac{\partial \mathcal{L}_{S}}{\partial u_{3}^{(k)}}\right] \bar{\nabla}_{\gamma} u_{\alpha}^{(k)} d S+ \\
+\int_{\partial S}\left(\frac{\partial \mathcal{L}_{S}}{\partial \bar{\nabla}_{\beta} u_{\alpha}^{(k)}} \bar{\nabla}_{\gamma} u_{\alpha}^{(k)}+\frac{\partial \mathcal{L}_{S}}{\partial \bar{\nabla}_{\beta} u_{3}^{(k)}} \bar{\nabla}_{\gamma} u_{3}^{(k)}\right) v_{\beta} d \Gamma+ \\
+\int_{\partial S}\left(\frac{\partial \mathcal{L}_{\partial S}}{\partial u_{\alpha}^{(k)}} \bar{\nabla}_{\gamma} u_{\alpha}^{(k)}+\frac{\partial \mathcal{L}_{\partial S}}{\partial u_{3}^{(k)}} \bar{\nabla}_{\gamma} u_{3}^{(k)}\right) d \Gamma .
\end{gathered}
$$

Accounting hence for the Lagrange equations (2.3) for plates [25-27], we have finally

$$
\begin{gathered}
\frac{d G_{\gamma}}{d t}=\int_{S}\left(\sigma_{(k)}^{\alpha \beta} v_{\beta}-\bar{q}_{B(k)}^{\alpha}\right) \bar{\nabla}_{\gamma} u_{\alpha}^{(k)} d \Gamma+ \\
+\int_{S}\left(\sigma_{(k)}^{3 \beta} v_{\beta}-\bar{q}_{B(k)}^{3}\right) \bar{\nabla}_{\gamma} u_{3}^{(k)} d \Gamma, \\
G_{\gamma}=\int_{S} \mathcal{G}_{\gamma} d S,
\end{gathered}
$$

where the covariant components of the wave momentum vector [30] are defined by (3.9):

$$
\mathcal{G}_{\gamma}=\frac{\partial \mathcal{L}_{S}}{\partial \dot{u}_{\alpha}^{(k)}} \bar{\nabla}_{\gamma} u_{\alpha}^{(k)}, \frac{\partial \mathcal{L}_{S}}{\partial \dot{u}_{3}^{(k)}} \bar{\nabla}_{\gamma} u_{3}^{(k)}
$$

Thus, the covariant components $G_{\gamma}$ of the total wave momentum vector (3.8) become the integrals of motion if the boundary conditions on $\partial S$ coinciding with the bracketed terms in the formula (3.7) are satisfied exactly.

The differential form of the field momentum conservation law can be written as follows:

$$
\dot{\mathcal{G}}_{\gamma}=\bar{\nabla}_{\beta} \mathcal{H}_{-\gamma}^{\beta \square},
$$

where the components of the Hamilton tensor are introduced by (3.11) accordingly to [40]:

$$
\begin{aligned}
& \mathcal{H}_{\llcorner\gamma}^{\beta \rrbracket}=\frac{\partial \mathcal{L}_{S}}{\partial \bar{\nabla}_{\beta} u_{\alpha}^{(k)}}-{ }_{\gamma} u_{\alpha}^{(k)}+ \\
& +\frac{\partial \mathcal{L}_{S}}{\partial \bar{\nabla}_{\beta} u_{3}^{(k)}} \bar{\nabla}_{\gamma} u_{3}^{(k)}-\delta_{\gamma}^{\beta} \mathcal{L}_{S} .
\end{aligned}
$$

Finally, the conservation law for the moments of wave momentum [30] can be formulated. Let us introduce the momentum moment field normal to the mid-plane $S$ of the plate:

$$
M_{3}=\int_{S} \mathcal{M}_{3} d S, \quad \mathcal{M}_{3}=\epsilon_{\gamma \delta}{ }^{\gamma} \mathcal{G}^{\delta}
$$

Similarly to the previously derived integral conservation laws, we obtain for the wave momentum moment (3.12) the following one: 
On Hamiltonian Formulations and Conservation Laws for Plate Theories of Vekua - Amosov Type

$$
\begin{gathered}
\frac{d M_{3}}{d t}=-\int_{S} \epsilon_{\beta \gamma} \mathcal{H}^{\beta \gamma} d S \\
+\int_{\partial S} \epsilon_{\delta \gamma} \xi^{\delta} a^{\gamma \varepsilon}\left(\sigma_{(k)}^{\alpha \beta} v_{\beta}-\bar{q}_{B(k)}^{\alpha}\right) \bar{\nabla}_{\varepsilon} u_{\alpha}^{(k)} d \Gamma+ \\
+\int_{\partial S} \epsilon_{\delta \gamma} \xi^{\delta} a^{\gamma \varepsilon}\left(\sigma_{(k)}^{3 \beta} v_{\beta}-\bar{q}_{B(k)}^{3}\right) \bar{\nabla}_{\varepsilon} u_{3}^{(k)} d \Gamma .
\end{gathered}
$$

The stress symmetry,

$$
\sigma^{\alpha \beta}=\sigma^{\beta \alpha},
$$

and the first term in (3.13) imply that the Hamilton tensor (3.11) is symmetric; the total moment of momentum (3.12) becomes integral of motion if the boundary conditions on the plate contour $\partial S$ are satisfied exactly.

\section{HAMILTON EQUATIONS}

\section{OF THE NTH ORDER PLATE THEORY IN TERMS OF THE INSTANTANEOUS" HAMILTON FORMALISM}

These equations can be obtained following J.B. Leech [30]. Let us consider the total differential of the Hamiltonian $\mathcal{H}^{0}$ :

$$
\begin{gathered}
d \mathcal{H}^{0}=\frac{\partial \mathcal{H}^{0}}{\partial u_{\alpha}^{(k)}} d u_{\alpha}^{(k)}+\frac{\partial \mathcal{H}^{0}}{\partial u_{3}^{(k)}} d u_{3}^{(k)}+ \\
+\frac{\partial \mathcal{H}^{0}}{\partial p_{(k)}^{\alpha}} d p_{(k)}^{\alpha}+\frac{\partial \mathcal{H}^{0}}{\partial \bar{\nabla}_{\beta} u_{\alpha}^{(k)}} d\left(\bar{\nabla}_{\beta} u_{\alpha}^{(k)}\right)+ \\
+\frac{\partial \mathcal{H}^{0}}{\partial p_{(k)}^{3}} d p_{(k)}^{3}+\frac{\partial \mathcal{H}^{0}}{\partial \bar{\nabla}_{\beta} u_{3}^{(k)}} d\left(\bar{\nabla}_{\beta} u_{3}^{(k)}\right) .
\end{gathered}
$$

On the other hand, from the definition for the $\mathcal{H}^{0}$ (3.3) we have accordingly to J. Leech [30]

$$
\begin{gathered}
d \mathcal{H}^{0}=\frac{\partial \mathcal{L}_{S}}{\partial u_{\alpha}^{(k)}} d u_{\alpha}^{(k)} \frac{\partial \mathcal{L}_{S}}{\partial u_{3}^{(k)}} d u_{3}^{(k)} \\
-\frac{\partial \mathcal{L}_{S}}{\partial \bar{\nabla}_{\beta} u_{\alpha}^{(k)}} d\left(\bar{\nabla}_{\beta} u_{\alpha}^{(k)}\right)-\frac{\partial \mathcal{L}_{S}}{\partial \bar{\nabla}_{\beta} u_{3}^{(k)}} d\left(\bar{\nabla}_{\beta} u_{3}^{(k)}\right)- \\
+p_{(k)}^{\alpha} \dot{u}_{\alpha}^{(k)}+p_{(k)}^{3} \dot{u}_{3}^{(k)}+\dot{u}_{\alpha}^{(k)} p_{(k)}^{\alpha}+\dot{u}_{3}^{(k)} p_{(k)}^{3},
\end{gathered}
$$

and the following relations can be derived:

$$
\begin{gathered}
\frac{\partial \mathcal{H}^{0}}{\partial u_{\alpha}^{(k)}}=-\frac{\partial \mathcal{L}_{S}}{\partial u_{\alpha}^{(k)}}, \quad \frac{\partial \mathcal{H}^{0}}{\partial u_{3}^{(k)}}=-\frac{\partial \mathcal{L}_{S}}{\partial u_{3}^{(k)}} ; \\
\frac{\partial \mathcal{H}^{0}}{\partial \bar{\nabla}_{\beta} u_{\alpha}^{(k)}}=-\frac{\partial \mathcal{L}_{S}}{\partial \bar{\nabla}_{\beta} u_{\alpha}^{(k)}} ; \\
\frac{\partial \mathcal{H}^{0}}{\partial \bar{\nabla}_{\beta} u_{3}^{(k)}}=-\frac{\partial \mathcal{L}_{S}}{\partial \bar{\nabla}_{\beta} u_{3}^{(k)}}
\end{gathered}
$$

as well as two Hamiltonian equations:

$$
\dot{u}_{\alpha}^{(k)}=\frac{\partial \mathcal{H}^{0}}{\partial p_{(k)}^{\alpha}}, \quad \dot{u}_{3}^{(k)}=\frac{\partial \mathcal{H}^{0}}{\partial p_{(k)}^{3}}
$$

Now let us consider the generalized momenta (3.4). Accounting for the Lagrange equations [25] results in the following relationships:

$$
\begin{aligned}
& \dot{p}_{(k)}^{\alpha}=\bar{\nabla}_{\beta} \frac{\partial \mathcal{H}^{0}}{\partial \bar{\nabla}_{\beta} u_{\alpha}^{(k)}}-\frac{\partial \mathcal{H}^{0}}{\partial u_{\alpha}^{(k)}} ; \\
& \dot{p}_{(k)}^{3}=\bar{\nabla}_{\beta} \frac{\partial \mathcal{H}^{0}}{\partial \bar{\nabla}_{\beta} u_{3}^{(k)}}-\frac{\partial \mathcal{H}^{0}}{\partial u_{3}^{(k)}} .
\end{aligned}
$$

They are the dynamics equations $[30,40]$ :

$$
\begin{gathered}
\left.\dot{p}_{(k)}^{\alpha}={ }_{\beta} \phi C_{(n m)}^{\alpha \beta \gamma \delta} \bar{\nabla}_{\delta} u_{\gamma}^{(m)}+C_{(n m)}^{\alpha \beta 3} u_{3}^{(m)}\right)- \\
-h^{-1} D_{(k \sqsubseteq)}^{([n)}\left(C_{(n m)}^{\alpha 33 \delta} \bar{\nabla}_{\delta} u_{3}^{(m)}+C_{(n m)}^{\alpha 3 \gamma} u_{\gamma}^{(m)}\right)+F_{(k)}^{\alpha} ; \\
\dot{p}_{(k)}^{3}=\bar{\nabla}_{\beta}\left(C_{(n m)}^{3 \beta 3 \delta} \bar{\nabla}_{\delta} u_{3}^{(m)}+\bar{C}_{(n m)}^{3 \beta \gamma} u_{\gamma}^{(m)}\right)+ \\
-h^{-1} D_{(k \sqsupset)}^{(\neg n)}\left(\bar{C}_{(n m)}^{33 \gamma \delta} \bar{\nabla}_{\delta} u_{\gamma}^{(m)}+\bar{C}_{(n m)}^{333} u_{3}^{(m)}\right)+F_{(k)}^{3}
\end{gathered}
$$


similar to the Lagrange equations [25-27]; their right hand sides contain second-order covariant derivatives of the field variables $u_{\alpha}^{(k)}, u_{3}^{(k)}$. The natural boundary conditions can be rewritten in the following notation:

$$
\begin{aligned}
& {\left.\left[v_{\beta} \frac{\partial \mathcal{H}^{0}}{\partial \bar{\nabla}_{\beta} u_{\alpha}^{(k)}}+\frac{\partial \mathcal{H}_{\partial S}}{\partial u_{\alpha}^{(k)}}\right] \delta u_{\alpha}^{(k)}\right|_{\partial S}=0} \\
& {\left.\left[v_{\beta} \frac{\partial \mathcal{H}^{0}}{\partial \bar{\nabla}_{\beta} u_{\alpha}^{(k)}}+\frac{\partial \mathcal{H}_{\partial S}}{\partial u_{\alpha}^{(k)}}\right] \delta u_{\alpha}^{(k)}\right|_{\partial S}=0}
\end{aligned}
$$

where formally

$$
\mathcal{H}_{\partial S}=\mathcal{L}_{\partial S}
$$

Finally, we have the initial conditions

$$
\begin{aligned}
& \left.u_{\alpha}^{(k)}\right|_{t=t_{0}}=U_{\alpha}^{(k)} ;\left.u_{3}^{(k)}\right|_{t=t_{0}}=U_{3}^{(k)} ; \\
& \left.p_{(k)}^{\alpha}\right|_{t=t_{0}}=P_{(k)}^{\alpha} ;\left.\quad p_{(k)}^{3}\right|_{t=t_{0}}=P_{(k)}^{3} .
\end{aligned}
$$

The obtained formulation (4.3), (4.5), (4.6), (4.7), and (4.8) corresponds to the so-called "instantaneous" Hamiltonian formulation for continuum systems that is based on the infinitedimensional phase spaces [42].

\section{HAMILTON - DE DONDER - WEYL EQUATIONS OF THE N-TH ORDER PLATE THEORY}

The Hamilton - de Donder - Weyl approach deals with finite dimensional phase spaces [41, 42] and is based on the set of polymomenta induced by spatial derivatives of field variables of the $1^{\text {st }}$ kind (2.7).

Let us construct the new Hamiltonian density depending on momenta and polymomenta using the Legendre transform considering both time and space derivatives of $\dot{u}_{\alpha}^{(k)}, \dot{u}_{3}^{(k)}$ :

$$
\begin{gathered}
\mathcal{H}^{D W}\left(u_{\alpha}^{(k)}, u_{3}^{(k)}, p_{(k)}^{\alpha}, p_{(k)}^{3}, \sigma_{(k)}^{\alpha \beta}, \sigma_{(k)}^{3 \beta}\right)= \\
=p_{(k)}^{\alpha} \dot{u}_{\alpha}^{(k)}+p_{(k)}^{3} \dot{u}_{3}^{(k)}+ \\
+\sigma_{(k)}^{\alpha \beta} \bar{\nabla}_{\beta} u_{\alpha}^{(k)}+\sigma_{(k)}^{3 \beta} \bar{\nabla}_{\beta} u_{3}^{(k)}-\mathcal{L}_{S}
\end{gathered}
$$

and let us compute its total differential:

$$
\begin{gathered}
d \mathcal{H}^{D W}=\frac{\partial \mathcal{H}^{D W}}{\partial p_{(k)}^{\alpha}} d p_{(k)}^{\alpha}+\frac{\partial \mathcal{H}^{D W}}{\partial p_{(k)}^{3}} d p_{(k)}^{3}+ \\
+\frac{\partial \mathcal{H}^{D W}}{\partial \sigma_{(k)}^{\alpha \beta}} d \sigma_{(k)}^{\alpha \beta}+\frac{\partial \mathcal{H}^{D W}}{\partial \sigma_{(k)}^{3 \beta}} d \sigma_{(k)}^{3 \beta}+ \\
+\frac{\partial \mathcal{H}^{D W}}{\partial u_{\alpha}^{(k)}} d u_{\alpha}^{(k)}+\frac{\partial \mathcal{H}^{D W}}{\partial u_{3}^{(k)}} d u_{3}^{(k)}
\end{gathered}
$$

On the other hand, from the definition given by Legendre transform (5.1) we obtain

$$
\begin{gathered}
d \mathcal{H}^{D W}=\dot{u}_{\alpha}^{(k)} d p_{(k)}^{\alpha}+\dot{u}_{3}^{(k)} d p_{(k)}^{3}+ \\
+\bar{\nabla}_{\beta} u_{\alpha}^{(k)} d \sigma_{(k)}^{\alpha \beta}+\bar{\nabla}_{\beta} u_{3}^{(k)} d \sigma_{(k)}^{3 \beta}+ \\
+p_{(k)}^{\alpha} d \dot{u}_{\alpha}^{(k)}+p_{(k)}^{3} d \dot{u}_{3}^{(k)}+ \\
+\sigma_{(k)}^{\alpha \beta} d\left(\bar{\nabla}_{\beta} u_{\alpha}^{(k)}\right)+\sigma_{(k)}^{3 \beta} d\left(\bar{\nabla}_{\beta} u_{3}^{(k)}\right)- \\
-\frac{\partial \mathcal{L}_{S}}{\partial \dot{u}_{\alpha}^{(k)}} d \dot{u}_{\alpha}^{(k)}-\frac{\partial \mathcal{L}_{S}}{\partial \dot{u}_{3}^{(k)}} d \dot{u}_{3}^{(k)}- \\
-\frac{\partial \mathcal{L}_{S}}{\partial \bar{\nabla}_{\beta} u_{\alpha}^{(k)}} d \bar{\nabla}_{\beta} u_{\alpha}^{(k)}-\frac{\partial \mathcal{L}_{S}}{\partial \bar{\nabla}_{\beta} u_{3}^{(k)}} d \bar{\nabla}_{\beta} u_{3}^{(k)}- \\
-\frac{\partial \mathcal{L}_{S}}{\partial u_{\alpha}^{(k)}} d u_{\alpha}^{(k)}-\frac{\partial \mathcal{L}_{S}}{\partial u_{3}^{(k)}} d u_{3}^{(k)},
\end{gathered}
$$

therefore we have the following relations for the partial derivatives of the Lagrangian and Hamiltonian surface densities:

$$
\frac{\partial \mathcal{H}^{D W}}{\partial u_{\alpha}^{(k)}}=-\frac{\partial \mathcal{L}_{S}}{\partial u_{\alpha}^{(k)}}, \quad \frac{\partial \mathcal{H}^{D W}}{\partial u_{3}^{(k)}}=-\frac{\partial \mathcal{L}_{S}}{\partial u_{3}^{(k)}}
$$

as well as the first pair of the canonical Hamilton - de Donder - Weyl equations: 


$$
\dot{u}_{\alpha}^{(k)}=\frac{\partial \mathcal{H}^{D W}}{\partial p_{(k)}^{\alpha}}, \quad \dot{u}_{3}^{(k)}=\frac{\partial \mathcal{H}^{D W}}{\partial p_{(k)}^{3}}
$$

and the second quasi-canonical pair:

$$
\bar{\nabla}_{\beta} u_{\alpha}^{(k)}=\frac{\partial \mathcal{H}^{D W}}{\partial \sigma_{(k)}^{\alpha \beta}}, \quad \bar{\nabla}_{\beta} u_{3}^{(k)}=\frac{\partial \mathcal{H}^{D W}}{\partial \sigma_{(k)}^{3 \beta}} \text {. }
$$

The equations (5.4) define the generalized velocities, or field variables of the $2^{\text {nd }}$ kind, whereas the equations (5.5) are constitutive relations represented in their inverse formulation and solved for the distortions.

Considering hence the Lagrange equations of (2.3) together with the definitions of momenta (3.4) and polymomenta (2.7), we obtain the last pair of quasi-canonical equations (5.6):

$$
\begin{aligned}
& \dot{p}_{(k)}^{\alpha}-\bar{\nabla}_{\beta} \sigma_{(k)}^{\alpha \beta}=-\frac{\partial \mathcal{H}^{D W}}{\partial u_{\alpha}^{(k)}} \\
& \dot{p}_{(k)}^{3}-\bar{\nabla}_{\beta} \sigma_{(k)}^{3 \beta}=-\frac{\partial \mathcal{H}^{D W}}{\partial u_{3}^{(k)}} .
\end{aligned}
$$

The equations (5.6) coincide with the equations (2.4) except the terms with $\sigma_{(k)}^{\alpha 3}, \sigma_{(k)}^{33}$ that are expressed through $u_{\alpha}^{(k)}, u_{3}^{(k)}$.

Finally, the natural boundary conditions (4.7) can be represented similarly to (2.5):

$$
\begin{aligned}
& \left.\left(\sigma_{(k)}^{\alpha \beta} v_{\beta}-\frac{\partial \mathcal{H}_{\Gamma}^{D W}}{\partial u_{\alpha}^{(k)}}\right)\right|_{\partial S}=0 ; \\
& \left.\left(\sigma_{(k)}^{3 \beta} v_{\beta}-\frac{\partial \mathcal{H}_{\Gamma}^{D W}}{\partial u_{\alpha}^{(k)}}\right)\right|_{\partial S}=0
\end{aligned}
$$

where formally $\mathcal{H}_{\Gamma}^{D W}=-\mathcal{L}_{\partial S}$ while the kinematic boundary conditions pair corresponds to the equations (5.5) in accordance with the approach shown in [39]. The initial conditions correspond to (4.8).

\section{CONCLUSIONS}

Starting from the Lagrangian formalism of the Vekua-Amosov general theory of thick plates, the conservation conditions are formulated, and the main motion integrals are constructed. It has to be noted that the presented plate model corresponds to the "elementary" theory that does not accounts for the boundary conditions on the faces of thin-walled structures. These boundary conditions are approximately satisfied as a result of the convergence of the twodimensional solutions sequence to the solution of the three-dimensional initial-boundary value problem. Thus, the nonzero energy flux vector field and the normal component of the secondrank Hamilton tensor due to the boundary conditions discrepancy appear on the mid-plane; the total Hamiltonian $H^{0}$ as well as the integral field momentum vector components $G_{\gamma}$ are therefore motion integrals under assumption of vanishing boundary conditions discrepancy as $N \rightarrow \infty$. In general, this drawback of "elementary" theories can be eliminated on the background of "extended" plate and shell theories (e. g. see [44-47]).

The Hamiltonian field equations for the Nth order plate theory are constructed. This formulation is variationally consistent and allows one the use of methods of lines in time domain for numerical solutions in transient plate dynamics' problems. On the other hand, the instantaneous Hamiltonian formulation can be considered as an "evolutionary" system of ordinary differential equations in time domain, or, with coefficients containing differential operators. This formalism maybe useful in various semi-analytical approaches such as [3134], [35] as well as [36-38].

The obtained de Donder - Weyl Hamiltonian $\mathcal{H}^{0}$ does not represent the total energy density [40] but allows one to construct the equations system that contains only first-order covariant derivatives. The obtained equations of Hamilton - de Donder - Weyl type (5.5) cannot be interpreted as canonical equations because of presence in their left hand sides the covariant 
derivatives; they can be rewritten nevertheless in the canonical representation by translating the terms with Christoffel symbols to their right hand sides. At the same time the dynamic equations (5.6) remain quasi-canonical due to the divergence operators and minus marks with the corresponding terms. The last drawback can be eliminated by means of different Hamiltonian construction (e. g. see [39]); the polymomenta definition also allows a certain degree of arbitrariness in the model formulation, so that the following general notation can be obtained:

$$
\begin{array}{ll}
\nabla^{*} \otimes \mathbf{U}=\frac{\partial \mathcal{H}}{\partial \mathbf{P}}, & \nabla^{*} \cdot \mathbf{P}=-\frac{\partial \mathcal{H}}{\partial \mathbf{U}}, \\
\mathbf{P}=\left\{\begin{array}{ll}
\mathbf{p} & \boldsymbol{\sigma}
\end{array}\right\}^{\mathrm{T}}, \quad \nabla^{*}=\left\{\begin{array}{ll}
\partial_{t} & \bar{\nabla}
\end{array}\right\} .
\end{array}
$$

The proposed Hamiltionian formulation can be considered only as a simplest one; its improvement become possible on the background of the powerful symplectic geometry formalism developed in the field theory $[40,41,43]$. Let us also note that the more complex Hamilton - Caratheodory formalism [41] offers nevertheless some features, at least in the numerical simulation, providing the use of Hamilton-Jacobi theory.

\section{ACKNOWLEDGEMENTS}

This investigation was financially supported by Russian Foundation for Basic Researches under grants Nr. 16-01-00751-a, Nr. 17-08-01461-a).

\section{REFERENCES}

1. Kienzler R., Altenbach H., Otts I. Theories of Plates and Shells: Critical Review and New Applications, SpringerVerlag, Berlin, 2004.

2. Eremeyev V., Pietraszkiewicz W. Refined theories of plates and shells // ZAMM. Vol. 94 (2014), pp. 5-6.
3. Zhou D., Au F.T.K., Cheung Y.K., Lo S.H. Three-dimensional vibration analysis of circular and annular plates via the Chebyshev-Ritz method // Int. J. Sol. Struct. Vol. 40 (2003), pp. 3089-3105.

4. Kang Jae-Hoon, Leissa A.W. ThreeDimensional Vibration Analysis of Thick, Complete Conical Shells // Trans. of ASME. Vol. 71 (2004), pp. 502-507.

5. Batra R.C., Aimmanee S. Vibrations of thick isotropic plates with higher order shear and normal deformable plate theories // Comput. and Struct. Vol. 83 (2005), pp. 934-955.

6. Carrera E., Brischetto S. Importance of higher order modes and refined theories in free vibration analysis of composite plates // J. Applied Math. Vol. 77 (2010), 011013 (14 $\mathrm{pp).}$

7. Carrera E., Zappino E. Carrera unified formulation for free vibration analysis of aircraft structures // AIAA Journal, Vol. 54, No. 1 (2016), pp. 280-292.

8. Matsunaga H. Free vibration and stability of functionally graded shallow shells according to a 2D higher-order deformation theory // Composite Structures. Vol. 84 (2008), pp. 132-146.

9. Kulikov G.M., Plotnikova S.V. Threedimensional solution of the free vibration problem for metal-ceramic shells using the method of sampling surfaces // Mech. Composite Mater. Vol. 53(2017), pp.1-14.

10. Gupta A., Talha M., Singh B.N. Vibration characteristics of functionally graded material plate with various boundary constraints using higher order shear deformation theory // Composites Pt. B: Enrg, Vol. 94 (2016), pp. 64-74.

11. Zernov V., Kaplunov J.D. Threedimensional edge waves in plates // Proc. Roy. Soc. Lond. A: Math. Phys. Engrg. Sci. Vol. 464 (2008), pp. 301-318.

12. Wilde M.V. Issledovanie javlenija kraevogo rezonansa $\mathrm{v}$ plastinah na osnove trehmernyh uravnenij teorii uprugosti [Investigation of the boundary resonance phenomenon in 
plates on the basis of the 3D elasticity theory equations]. // Mech. Deform. Media, Saratov Univ., Issue 16 (2010), pp. 7-14.

13. Wilde M.V. Kromochnye volny vysshego porjadka $\mathrm{v}$ tonkoj plastine [Higher order edge waves in thick plates]. // Vestn. Lobachevsky Univ. N. Novgorod, Issues 4-5 (2011), pp. 2060-2062.

14. Abrosimov N.A., Novosel'tseva N.A. The identification of material parameters in nonlinear deformation models of metallicplastic cylindrical shells under pulsed loadings // Mater. Phys. Mech. Vol. 23 (2015), pp. 66-70.

15. Goldenweiser A.L. Theory of Thin Elastic Shells. Int. Ser. of Monograph in Aeronautics and Astronautics, Pergamon Press, N. Y. 1961.

16. Berdichevskiy V.L. Variational methods of constructing models of shells // J. of Applied Mathematics and Mechanics. Vol. 36 (1972), pp. 743-758.

17. Vekua I. N. Shell Theory: General Methods of Construction, Pitman Advanced Publ. Program, Boston, 1985.

18. Khoma I.Yu. Obobshhennaja teorija anizotropnyh obolochek [General Anisotropic Shell Theory]. Kiev, Naukova Dumka, 1986.

19. Gordeziani D., Avalishvili M., Avalishvili G. Hierarchical models for elastic shells in curvilinear coordinates // Comput. Math. Appl. Vol. 51 (2006), pp. 1789-1808.

20. Meunargia T. Some general methods for constructing the theory of shells // J. Math. Sci. Vol.157, No.1(2009), pp. 1-15.

21. Guliaev V.I., Bazhenov B.A., Lizunov P.P. Neklassicheskaja teorija obolochek i ee prilozhenie $\mathrm{k}$ resheniju inzhenernyh zadach [Nonclassical Shell Theory and Applications in Engineering]. Lvov, Vishcha Shkola, 1978.

22. Amosov A.A. An approximate threedimensional theory of thick plates and shells // Structural Mechanics and Design of Buildings, No. 5 (1987), pp. 37-42.
23. Amosov A.A., Zhavoronok S.I. An approximate high-order theory of thick anisotropic shells // International Journal of Computational Civil and Structural Engineering. Vol. 1 (2003), pp. 28-38.

24. Zhavoronok S.I. Modeli vysshego porjadka anizotropnyh obolochek [High-order anisotropic shells models]. // The Journal of Mekhanika Kompozitsionnykh Materialov i Konst-ruktsii. Vol.14, No. 4 (2008), pp. 561-571.

25. Zhavoronok S.I. Obobshhennye uravnenija Lagranzha vtorogo roda trehmernoj teorii anizotropnyh obolochek [Generalized Lagrange equations of the second kind of three-dimensional anisotropic shell theory]. // The Journal of Mekhanika Kompozitsionnykh Materialov i Konstruktsii. Vol. 17 (2011), pp. 116-132.

26. Zhavoronok S.I. A Vekua-type linear theory of thick elastic shells // ZAMM. Vol. 94 (2014), pp. 164-184.

27. Zhavoronok S.I. Variational formulations of Vekua-type shell theories and some their applications. Shell Structures: Theory and Applications, Vol. 3, eds: W. Pietraszkiewicz, J. Gorski, CRC Press / Balkema, Taylor \& Francis Gr., Leiden (2014), pp. 341-344.

28. Zhavoronok S.I. Issledovanie kinematiki normal'nyh voln $\mathrm{v}$ uprugom sloe na osnove trehmernoj teorii obolochek N-go porjadka dlja razlichnyh znachenij volnovyh chisel [Kinematics of normal modes in elastic layer for some wavenumbers investigation based on $\mathrm{N}$-th order three-dimensional shells' theory]. // The Journal of Mekhanika Kompozitsion-nykh Materialov i Konstruktsii. Vol. 18 (2012), pp. 45-56.

29. Zhavoronok S.I. A Formulation of the three-dimensional approximated shells theory of $\mathrm{N}$-th order using generalized displacements and its application to steady dynamics // The Journal of Mekhanika Kompozitsionnykh Materialov i Konstruktsii. Vol.18 (2012), pp. 333-344. 
30. Leech J. W. Classical Mechanics. London: Methuen and Co Ltd; New York: Wiley and Sons, 1958.

31. Changcheng Du, Yinghui Li. Nonlinear resonance of functionally graded cylindrical shells using the Hamiltonian dynamics // Acta Mech. Solida Sinica. Vol. 27 (2014), pp. 635-647.

32. Tarn J.-Q., Chang H.-H., Tseng W.-D. Axisymmetric Deformation of a Transversely Isotropic Cylindrical Body: A Hamiltonian State-Space Approach // J. Elast. Vol. 97 (2009), pp. 131-154.

33. Tarn J.-Q., Chang H.-H., Tseng W.-D. A Hamiltonian State Space Approach for 3D Analysis of Circular Cantilevers // J. Elast. Vol. 101 (2010), pp. 207-237.

34. Chang H.-H., Tarn J.-Q. ThreeDimensional Elasticity Solutions for Rectangular Orthotropic Plates // J. Elast. Vol. 108 (2012), pp. 49-66.

35. Tarn J.-Q., Tseng W.-D. Exact Analysis of Curved Beams and Arches with Arbitrary End Conditions: A Hamiltonian State Space Approach // J. Elast. Vol. 107 (2012), pp. 39-63.

36. Akimov P.A. Correct discrete-continual finite element method of structural analysis based on precise analytical solutions of resulting multipoint boundary problems for systems of ordinary differential equations // Appl.Mech.Mater. Vols. 204-208 (2012), pp. 4502-4505.

37. Akimov P.A., Negrozov O.A. O nekotoryh napravlenijah razvitija korrektnyh diskretnokontinual'nyh metodov mnogourovnevogo rascheta konstrukcij [About one sample of deep beam analysis based on combined application of finite element method and discrete-continual finite element method]. // International Journal of Computational Civil and Structural Engineering. Vol. 11, Issue (2015), pp. 14-28.

38. Akimov P.A., Mozgaleva M.L., Aslami M., Negrozov O.A. O nekotoryh napravlenijah razvitija korrektnyh diskretnokontinual'nyh metodov mnogourovnevogo rascheta konstrukcij [On some paths of development of the correct discretecontinual methods of multi-level computing of structures]. // The Journal of Mekhanika Kompozitsionnykh Materialov i Konstruktsii. Vol.21(2015), pp. 469-488.

39. Kilchevskiy N.A., Kilchinskaya G.A., Tkachenko N.E. Analiticheskaja mehanika kontinual'nyh sistem [Analytical Mechanics of Continuum Systems]. Kiev, Naukova Dumka, 1979.

40. Kastrup H.A. Canonical theories of Lagrangian dynamical systems in physics // Phys. Reports (Review Sect. of Phys. Lett.) Vol. 101 (1983), pp. 1-167.

41. Kanatchikov I.V. Canonical structure of classical field theory in the polymomentum phase space // Reports Math. Phys. Vol. 41 (1988), pp. 49-90.

42. Grinchenko V.T., Meleshko V.V. Garmonicheskie kolebanija i volny v uprugih telah [Harmonic oscillations and waves in elastic solids]. Kiev, Naukova Dumka, 1981.

43. Giachetta G., Mangarotti L., Sardanashvili G. New Lagrangian and Hamiltonian Methods in Filed Theory. Singapore, World Scientific, 1997.

44. Zhavoronok S. I. On the variational formulation of the extended thick anisotropic shells theory of I. N. Vekua type // Procedia Engineering. Vol. 111 (2015), pp. 888-895.

45. Zhavoronok S. I. Obobshhennye uravnenija Lagranzha vtorogo porjadka rasshirennoj trehmernoj teorii N-go porjadka anizotropnyh obolochek [The generalized Lagrange equations of the second kind for the extended three-dimensional Nth order theory of anisotropic shells]. // The Journal of Mekhanika Kompozitsionnykh Materialov i Konstruktsii. Vol. 21 (2015), pp. 370-381.

46. Zhavoronok S. I. The extended shell theory of Vekua-Amosov type and the low-order plate models // International Journal for 
Computational Civil and Structural Engineering. Vol. 12 (2016), pp. 27-35.

47. Zhavoronok S. I. A general higher-order shell theory based on the analytical dynamics of constrained continuum systems. Shell Structures: Theory and Applications, Vol. 4. CRC Press / Balkema, Taylor \& Francis Gr., Leiden (2017), pp. 189-192.

\section{СПИСОК ЛИТЕРАТУРЫ}

1. Kienzler R., Altenbach H., Otts I. Theories of Plates and Shells: Critical Review and New Applications, SpringerVerlag, Berlin, 2004.

2. Eremeyev V., Pietraszkiewicz W. Refined theories of plates and shells // ZAMM. Vol. 94 (2014), pp. 5-6.

3. Zhou D., Au F.T.K., Cheung Y.K., Lo S.H. Three-dimensional vibration analysis of circular and annular plates via the Chebyshev-Ritz method // Int. J. Sol. Struct. Vol. 40 (2003), pp. 3089-3105.

4. Kang Jae-Hoon, Leissa A. W. ThreeDimensional Vibration Analysis of Thick, Complete Conical Shells // Trans. of ASME. Vol. 71 (2004), pp. 502-507.

5. Batra R. C., Aimmanee S. Vibrations of thick isotropic plates with higher order shear and normal deformable plate theories // Comput. and Struct. Vol. 83 (2005), pp. 934-955.

6. Carrera E., Brischetto S. Importance of higher order modes and refined theories in free vibration analysis of composite plates // J. Applied Math. Vol. 77 (2010), 011013 (14 $\mathrm{pp).}$

7. Carrera E., Zappino E. Carrera unified formulation for free vibration analysis of aircraft structures // AIAA Journal, Vol. 54, No. 1 (2016), pp. 280-292.

8. Matsunaga H. Free vibration and stability of functionally graded shallow shells according to a 2D higher-order deformation theory // Composite Structures. Vol. 84 (2008), pp. 132-146.
9. Kulikov G.M., Plotnikova S.V. Threedimensional solution of the free vibration problem for metal-ceramic shells using the method of sampling surfaces // Mech. Composite Mater. Vol. 53(2017), pp.1-14.

10. Gupta A., Talha M., Singh B.N. Vibration characteristics of functionally graded material plate with various boundary constraints using higher order shear deformation theory // Composites Pt. B: Enrg, Vol. 94 (2016), pp. 64-74.

11. Zernov V., Kaplunov J.D. Threedimensional edge waves in plates // Proc. Roy. Soc. Lond. A: Math. Phys. Engrg. Sci. Vol. 464 (2008), pp. 301-318.

12. Вильде М.В. Исследование явления краевого резонанса в пластинах на основе трехмерных уравнений теории упругости. // Механика деформируемых сред, №16, 2010, c. 7-14.

13. Вильде М.В. Кромочные волны высшего порядка в тонкой пластине. // Вестник Нижегородского университета им. Н.И. Лобачевского, №4-5, 2011, с. 2060-2062.

14. Abrosimov N.A., Novosel'tseva N.A. The identification of material parameters in nonlinear deformation models of metallicplastic cylindrical shells under pulsed loadings // Mater. Phys. Mech. Vol. 23 (2015), pp. 66-70.

15. Goldenweiser A.L. Theory of Thin Elastic Shells. Int. Ser. of Monograph in Aeronautics and Astronautics, Pergamon Press, N. Y. 1961.

16. Berdichevskiy V.L. Variational methods of constructing models of shells // J. of Applied Mathematics and Mechanics. Vol. 36 (1972), pp. 743-758.

17. Vekua I.N. Shell Theory: General Methods of Construction, Pitman Advanced Publ. Program, Boston, 1985.

18. Хома И.Ю. Обобщенная теория анизотропных оболочек. - Киев: Наукова думка, 1986. - 172 с.

19. Gordeziani D., Avalishvili M., Avalishvili G. Hierarchical models for elastic shells in 
curvilinear coordinates // Comput. Math. Appl. Vol. 51 (2006), pp. 1789-1808.

20. Meunargia T. Some general methods for constructing the theory of shells // J. Math. Sci. Vol.157, No.1(2009), pp. 1-15.

21. Гуляев В.И., Баженов В.А., Лизунов П.П. Неклассическая теория оболочек и ее приложение к решению инженерных задач. - Львов: Вища школа, 1978. - 192 с.

22. Amosov A.A. An approximate threedimensional theory of thick plates and shells // Structural Mechanics and Design of Buildings, No. 5 (1987), pp. 37-42.

23. Amosov A.A., Zhavoronok S.I. An approximate high-order theory of thick anisotropic shells. // International Journal of Computational Civil and Structural Engineering. Vol. 1 (2003), pp. 28-38.

24. Жаворонок С.И. Модели высшего порядка анизотропных оболочек. // Механика композиционных материалов и конструкций, Том 14, Номер 4, 2008, с. 561-571.

25. Жаворонок С.И. Обобщенные уравнения Лагранжа второго рода трехмерной теории анизотропных оболочек. // Механика композиционных материалов и конструкций, Том 17, Номер 1, 2011, c. 116-132.

26. Zhavoronok S.I. A Vekua-type linear theory of thick elastic shells // ZAMM. Vol. 94 (2014), pp. 164-184.

27. Zhavoronok S.I. Variational formulations of Vekua-type shell theories and some their applications. Shell Structures: Theory and Applications, Vol. 3, eds: W. Pietraszkiewicz, J. Gorski, CRC Press / Balkema, Taylor \& Francis Gr., Leiden (2014), pp. 341-344.

28. Жаворонок С.И. Исследование кинематики нормальных волн в упругом слое на основе трехмерной теории оболочек N-го порядка для различных значений волновых чисел. // Механика композиционных материалов и конструкций, Том 18, Номер 1, 2012, с. 45-56.
29. Zhavoronok S.I. A Formulation of the three-dimensional approximated shells theory of $\mathrm{N}$-th order using generalized displacements and its application to steady dynamics. // Механика композиционных материалов и конструкций, Том 18 , Номер 3, 2012, с. 333-344.

30. Leech J.W. Classical Mechanics. London: Methuen and Co Ltd; New York: Wiley and Sons, 1958.

31. Changcheng Du, Yinghui Li. Nonlinear resonance of functionally graded cylindrical shells using the Hamiltonian dynamics // Acta Mech. Solida Sinica. Vol. 27 (2014), pp. 635-647.

32. Tarn J.-Q., Chang H.-H., Tseng W.-D. Axisymmetric Deformation of a Transversely Isotropic Cylindrical Body: A Hamiltonian State-Space Approach // J. Elast. Vol. 97 (2009), pp. 131-154.

33. Tarn J.-Q., Chang H.-H., Tseng W.-D. A Hamiltonian State Space Approach for 3D Analysis of Circular Cantilevers // J. Elast. Vol. 101 (2010), pp. 207-237.

34. Chang H.-H., Tarn J.-Q. ThreeDimensional Elasticity Solutions for Rectangular Orthotropic Plates // J. Elast. Vol. 108 (2012), pp. 49-66.

35. Tarn J.-Q., Tseng W.-D. Exact Analysis of Curved Beams and Arches with Arbitrary End Conditions: A Hamiltonian State Space Approach // J. Elast. Vol. 107 (2012), pp. 39-63.

36. Akimov P.A. Correct discrete-continual finite element method of structural analysis based on precise analytical solutions of resulting multipoint boundary problems for systems of ordinary differential equations // Appl.Mech.Mater. Vols. 204-208 (2012), pp. 4502-4505.

37. Акимов П.А., Негрозов О.А. Об одном примере расчета балки-стенки на основе совместного применения метода конечных элементов и дискретноконтинуального метода конечных элементов. // International Journal of Computational Civil and Structural 
Engineering. Vol. 11, Issue 4 (2015), pp. 14-28.

38. Акимов П.А., Мозгалева М.Л., Моджтаба Аслами, Негрозов О.А. О некоторых направлениях развития корректных дискретно-континуальных методов многоуровневого расчета конструкций. // Механика композиционных материалов и конструкций, Том 21, Номер 4, 2015, с. 469-488.

39. Кильчевский Н.А., Кильчинская Г.А., Ткаченко Н.Е. Аналитическая механика континуальных систем. - Киев: Наука, думка, 1979. - 188 с.

40. Kastrup H.A. Canonical theories of Lagrangian dynamical systems in physics // Phys. Reports (Review Sect. of Phys. Lett.) Vol. 101 (1983), pp. 1-167.

41. Kanatchikov I.V. Canonical structure of classical field theory in the polymomentum phase space // Reports Math. Phys. Vol. 41 (1988), pp. 49-90.

42. Гринченко В.Т., Мелешко В.В. Гармонические колебания и волны в упругих телах. - Киев: Наукова думка, 1981. - 284 c.

43. Giachetta G., Mangarotti L., Sardanashvili G. New Lagrangian and Hamiltonian Methods in Filed Theory. Singapore, World Scientific, 1997.

44. Zhavoronok S. I. On the variational formulation of the extended thick anisotropic shells theory of I. N. Vekua type // Procedia Engineering. Vol. 111 (2015), pp. 888-895.

45. Жаворонок С.И. Обобщенные уравнения Лагранжа второго порядка расширенной трехмерной теории $\mathrm{N}$-го порядка анизотропных оболочек. // Механика композиционных материалов и конструкций, Том 21, Номер 3, 2015, с. 370-381.

46. Zhavoronok S. I. The extended shell theory of Vekua-Amosov type and the low-order plate models // International Journal for Computational Civil and Structural
Engineering. Vol. 12, Issue 4 (2016), pp. $27-$ 35.

47. Zhavoronok S. I. A general higher-order shell theory based on the analytical dynamics of constrained continuum systems. Shell Structures: Theory and Applications, Vol. 4. CRC Press / Balkema, Taylor \& Francis Gr., Leiden (2017), pp. 189-192.

Zhavoronok Sergey Igorevich, Ph.D., Senior researcher of the Department of Mechanics of Smart and Composite Materials and Systems, Institute of Applied Mechanics of Russian Academy of Sciences; Associate Professor of the Department of Strength of Materials, Machine Dynamics and Strength, Moscow Aviation Institute (National Research University); Address: Leningradskiy Prospekt 7, 125040, Moscow, Russia.

Phone: +7(495) 941-1777; +7(916) 134-2843.

e-mail: Zhavoronok@iam.ras.ru, zhavor71@mail.ru

Жаворонок Сергей Игоревич, кандидат физикоматематических наук, старший научный сотрудник, Институт прикладной механики Российской академии наук (ИПРИМ РАН); доцент кафедры сопротивления материалов, Московский авиационный институт (национальный исследовательский университет); 125 040, г. Москва, Ленинградский проспект, д. 7, стр. 1; тел. +7(495) 941-1777; +7(916) 134-2843.

e-mail: Zhavoronok@iam.ras.ru, zhavor71@mail.ru 